\title{
Postnonclassical Methodology in Clinical Psychology: Opportunities and Perspectives of Vygotsky-Luria School
}

\author{
Elena Pervichko, Yury Zinchenko \\ Faculty of Psychology, Lomonosov Moscow State University, Moscow, Russia \\ Email: elena pervichko@mail.ru, zinchenko y@mail.ru
}

Received January 2014

\begin{abstract}
The primary aim of this research is to show the high efficacy of the psychological syndrome analysis (Vygotsky-Luria School) for a variety of issues embraced by psychodiagnostics and psychotherapy. The syndrome approach applied in theoretical and practical fields of clinical psychology is highly efficient at the current state of science evolution. The principal method of this study was the psychological syndrome analysis. We examined 85 patients with hypertension (HTN) at work and 85 essential HTN patients. The results suggest that the psychosomatic syndrome has a multifactorial structure. That is, the structure of the psychosomatic syndrome in patients with HTN at work is determined by three factors. These are as follows: the motivational factor (characterized by the domination of the achievement motivation); the factor of emotion regulation disorder; and the factor of repression and denial of the significance of an alarming situation.
\end{abstract}

\section{Keywords}

Postnonclassical Methodology, Clinical Psychology, Psychological Syndrome Analysis, Vygotsky-Luria School, Psychosomatic Syndrome, Essential Hypertension, Hypertension at Work

\section{Introduction}

In recent times the Russian psychology has witnessed repeated attempts of methodological analysis of psychological concepts conducted on the basis of a well-known classification of the types of scientific rationality, suggested by V.S. Styopin. The classification provides grounds for designation of the following types (and stages) in development of scientific knowledge: classical, nonclassical and postnonclassical [1]-[6]. To study objects represented in elementary systems the means of classical science will suffice; non-classical science should operate with self-regulating systems, and postnonclassical science may cope with complex self-developing systems [1]. "Selfdeveloping systems are capable of switching from one type of self-adjustment to another. ... They can become more complicated in the process of development, increase the number of levels in the hierarchical organization of their elements. The formation of each new level has a reverse effect on the already established ones, it changes them" [1] [7]. 
The principle of syndrome analysis of psychic phenomena is one of the most essential methodological principles in Russian clinical psychology (the Vygotsky-Luria school) [4] [5] [7] [8]. We presume that the syndrome approach applied in theoretical and practical fields of clinical psychology is highly efficient at the current state of the evolution of science due to the potential of the new methodological context of the postnonclassical model of rationality and a comprehensive character of cultural-historical theory proposed by L.S. Vygotsky and A.R. Luria regarding the person and his/her mind as a self-developing open systems.

\section{Research Objectives}

The primary aim of this research is to show the high efficacy of the psychological syndrome analysis (Vygotsky-Luria school) for solving issues in the field of psychodiagnostics and psychotherapy within the framework of postnonclassical methodology.

Hypertension (HTN) is one of the most dangerous and common diseases of cardiovascular system. Today there detected more and more patients with HTN, whose blood pressure (BP) values at work time appear to be higher than those at leisure. This form of HTN is called "HTN at work" [9]. Studies of emotional and personality characteristics of patients with HTN at work indicated that they usually experience negative emotions in more prolonged and excessive way with a tendency not to express them openly [10]-[14].

We take an example of description of a psychosomatic syndrome in patients with HTN at work to demonstrate that a psychosomatic syndrome may serve as a means not only for establishing a diagnosis, but for evidence of the role of stress in BP increase, and for making psychological and clinical prognoses for each particular patient.

\section{Research Methods and Design}

The principal method of this research was psychological syndrome analysis (Vygotsky-Luria school). The research was carried out with the implication of methods of psychological experiment and psychological testing, and methods of physiological data registration. A stressful situation was created experimentally, employing the procedure of aspiration level (AL) research. A situation was set up that induced a state of mental tension. In the course of the experiment participants were asked to solve 12 tasks. As stimulating material Raven's Progressive Matrices were suggested. Before and after the experiment participants' level of state anxiety (SA) (the Spielberger SA Inventory), and physiological indices (BP reaction, catecholamines (CA) level in urine, rennin and angiotensin 1 $\left(\mathrm{A}_{1}\right)$ level in blood plasma) were assessed. In the course of experiment there were estimated features of AL and characteristics of participants' nonverbal behavior. The clinical and physiological part of the study was conducted on participatory terms with specialists in Department of General medicine at the Moscow State University of Medicine and Dentistry (Professor E.I. Sokolov, Professor O.D. Ostroumova). Statistical processing of the data was conducted with implication of various methods: calculation of mean values and the standard deviation; frequency analysis; certainty computation for distinctions between samples based on indicators of the probability of distinctions between indicators (Mann-Whitney U-test). Cluster analysis (Hierarchical clustering method) was used for solving the task of feature combination in relatively homogeneous groups.

The study comprised 85 participants with HTN at work, mean age was $44.7 \pm 4.3$ years, and 85 patients with essential HTN, mean age was $47.4 \pm 4.5$ years.

\section{Results and Their Discussion}

The received results showed that within our research employing experimental stress modeling, a state of emotional tension was formed in practically all the patients with HTN. This fact is confirmed by BP and SA increase in all the patients with HTN in the course of experiment (Table 1, and Table 2). However, some patients with HTN were characterized not by increase (which is regarded as a norm for stressful reaction), but decrease of indices of all measured biochemical parameters, as well as by decrease of SA level (Table 3, and Table 4). Besides, patients with decrease of biochemical and SA indices in the course of stress-modeling were also characterized by initially lower indices of CA in urine, and renin and $A_{I}$ in blood plasma (Table 4). This may be accounted for by the absence of essential biochemical "pre-race readiness", exceedingly important for entering a stressful situation and efficient coping with it. On the basis of statistical data analysis we may conclude that HTN at work patients demonstrate more significant stress reactions, which in certain cases appear paradoxical (Tables 1-4). Patients with HTN at work also differ from patients with essential HTN by initially higher level of 
Table 1. Average blood pressure indices in the compare groups of HTN patients (mmHg).

\begin{tabular}{cccc}
\hline Blood pressure indices & $\begin{array}{c}\text { Patients with } \mathrm{HTN} \text { at work, } \\
\mathrm{n}=85(\mathrm{Me} \pm \mathrm{SD})\end{array}$ & $\begin{array}{c}\text { Patients with essential HTN, } \\
\mathrm{n}=85(\mathrm{Me} \pm \mathrm{SD})\end{array}$ & $\begin{array}{c}\text { Significant difference on the } \\
\text { Mann-Whitney U-test }\end{array}$ \\
\hline Systolic BP before experiment & $141.0 \pm 3.5$ & $149.0 \pm 3.8$ & - \\
Systolic BP after experiment & $157.1 \pm 4.1$ & $153.1 \pm 4.0$ & - \\
$\Delta$ Systolic BP & $16.1 \pm 1.9$ & $4.1 \pm 0.7$ & - \\
Diastolic BP before experiment & $92.8 \pm 2.0$ & $98.9 \pm 2.4$ & - \\
Diastolic BP after experiment & $97.3 \pm 2.9$ & $101.3 \pm 2.8$ & $p<0.05$ \\
$\Delta$ Diastolic BP & $4.5 \pm 0.7$ & $2.4 \pm 0.5$ & - \\
\hline
\end{tabular}

Table 2. Average indices of satate anxiety level in the compare groups of HTN patients (points).

\begin{tabular}{cccc}
\hline State anxiety level & $\begin{array}{c}\text { Patients with } \mathrm{HTN} \text { at work, } \\
\mathrm{n}=85(\mathrm{Me} \pm \mathrm{SD})\end{array}$ & $\begin{array}{c}\text { Patients with essential HTN, } \\
\mathrm{n}=85(\mathrm{Me} \pm \mathrm{SD})\end{array}$ & $\begin{array}{c}\text { Significant difference on the } \\
\text { Mann-Whitney U-test }\end{array}$ \\
\hline SA before experiment & $42.8 \pm 3.6$ & $37.0 \pm 2.3$ & $\mathrm{p}<0.05$ \\
SA after experiment & $45.2 \pm 2.9$ & $38.3 \pm 2.0$ & $\mathrm{p}<0.05$ \\
$\Delta$ SA & $2.4 \pm 0.5$ & $1.3 \pm 0.2$ & $\mathrm{p}<0.05$ \\
\hline
\end{tabular}

Table 3. Frequency of positive and negative changes of satate anxiety level in HTN patients (\%).

\begin{tabular}{cccc}
\hline \multirow{2}{*}{ Pattern of SA change after experiment } & $\begin{array}{c}\text { Patients with HTN at } \\
\text { work, } \mathrm{n}=85\end{array}$ & $\begin{array}{c}\text { Patients with essential } \\
\text { HTN, } \mathrm{n}=85\end{array}$ & $\begin{array}{c}\text { Significant difference on the } \\
\text { Mann-Whitney U-test }\end{array}$ \\
\cline { 2 - 3 } SA increases after experiment, $\mathrm{SA}_{2}>\mathrm{SA}_{1}$ & Abs. value (\%) & Abs. value (\%) & $58(68.2 \%)$ \\
SA decreases after experiment, $\mathrm{SA}_{2}<\mathrm{SA}_{1}$ & $51(36.5 \%)$ & $27(31.8 \%)$ & $\mathrm{p}<0.05$ \\
\hline
\end{tabular}

Table 4. Lavels of catecholamines in urine, renin, and angiotensin 1 in blood plasma in HTN patients.

\begin{tabular}{|c|c|c|c|c|}
\hline \multicolumn{2}{|c|}{ Parameters } & $\begin{array}{c}\text { Patients with HTN at work, } \\
n=85(\mathrm{Me} \pm \mathrm{SD})\end{array}$ & $\begin{array}{l}\text { Patients with essential HTN, } \\
n=85(\mathrm{Me} \pm \mathrm{SD})\end{array}$ & $\begin{array}{l}\text { Significant difference on the } \\
\text { Mann-Whitney U-test }\end{array}$ \\
\hline \multirow{2}{*}{$\begin{array}{c}\text { Adrenaline, } \\
\mathrm{nmol} / \mathrm{s}\end{array}$} & Before experiment & $81.7 \pm 0.2$ & $119.8 \pm 0.2$ & $\mathrm{p}<0.05$ \\
\hline & After experiment & $54.3 \pm 0.2^{*}$ & $211.4 \pm 0.2^{*}$ & $\mathrm{p}<0.001$ \\
\hline \multirow{2}{*}{$\begin{array}{c}\text { Noradrenaline, } \\
\text { nmol/s }\end{array}$} & Before experiment & $151.6 \pm 0.3$ & $182.1 \pm 0.3$ & $\mathrm{p}<0.05$ \\
\hline & After experiment & $138.6 \pm 0.3^{*}$ & $329.2 \pm 0.3^{*}$ & $\mathrm{p}<0.001$ \\
\hline \multirow{2}{*}{ Renin, $(\mathrm{ngr} / \mathrm{ml}) / \mathrm{s}$} & Before experiment & $1.04 \pm 0.21$ & $0.86 \pm 0.21$ & - \\
\hline & After experiment & $0.84 \pm 0.01^{*}$ & $0.96 \pm 0.01^{*}$ & - \\
\hline \multirow{2}{*}{$\begin{array}{l}\text { Angiotensin } 1 \text {, } \\
(\mathrm{ngr} / \mathrm{ml}) / \mathrm{s}\end{array}$} & Before experiment & $1.14 \pm 0.13$ & $1.26 \pm 0.09$ & - \\
\hline & After experiment & $0.96 \pm 0.03^{*}$ & $1.35 \pm 0.03^{*}$ & - \\
\hline
\end{tabular}

Note: *Differences in the data before and after the experiment are significant $(\mathrm{p}<0.05)$.

SA, reliably higher but inadequate and instable $\mathrm{AL}$, and more intensive gesticulation, facial expression, and also active voice modulation (Tables 2,5 , and $\mathbf{6}$ ).

Cluster analysis of the data confirmed the hypothesis of general heterogeneity of patients with HTN, as well as internal heterogeneity of the compared groups of patients with HTN. Three well-interpreted clusters were statistically marked out; they embrace psychological, physiological and behavioral parameters, which made it possible to describe 3 subgroups inside the groups of patients with HTN:

- Patients with openly anxious reaction type (91 patients, $53.5 \%$ of all participants with HTN). Patients from this group are characterized by significant increase of SA level in the course of experiment, open emotion expression, a rich variety of behavioral exposure accompanied by a slight BP growth and increase of A, NA, renin and AI level in the course of experiment.

- Patients with excessive emotion repression (70 people, $41.2 \%$ of participants with HTN). They showed a significant growth of systolic BP level, initially lower A and NA levels and decrease in the course of expe- 
Table 5. Frequency of aspiration level characteristics in the compare groups of HTN patients (\%).

\begin{tabular}{ccccc}
\hline Aspiration level characteristics & $\begin{array}{c}\text { Patients with HTN at } \\
\text { work, } \mathrm{n}=85\end{array}$ & $\begin{array}{c}\text { Patients with essential } \\
\text { HTN, } \mathrm{n}=85\end{array}$ & $\begin{array}{c}\text { Significant difference on the } \\
\text { Mann-Whitney U-test }\end{array}$ \\
\hline \multirow{3}{*}{ Height } & High AL & 71.7 & 75.3 & - \\
& Middle AL & 16.5 & 16.5 & - \\
\multirow{5}{*}{ Stability } & Low AL & 11.8 & 8.2 & $\mathrm{p}<0.05$ \\
& Stable AL & 43.5 & 60.0 & $\mathrm{p}<0.05$ \\
\multirow{3}{*}{ Adequacy } & Unstable AL & 56.5 & 40.0 & $\mathrm{p}<0.05$ \\
& Adequate AL & 30.6 & 43.5 & $\mathrm{p}<0.05$ \\
\hline
\end{tabular}

Table 6. Average values of nonverbal behaviors in the compare groups of HTN patients (points).

\begin{tabular}{cccc}
\hline Nonverbal behaviors & $\begin{array}{c}\text { Patients with HTN at work, } \\
\mathrm{n}=85(\mathrm{Me} \pm \mathrm{SD})\end{array}$ & $\begin{array}{c}\text { Patients with essential HTN, } \\
\mathrm{n}=85(\mathrm{Me} \pm \mathrm{SD})\end{array}$ & $\begin{array}{c}\text { Significant difference on the } \\
\text { Mann-Whitney U-test }\end{array}$ \\
\hline Gestures & $18.3 \pm 2.8$ & $21.6 \pm 2.9$ & $\mathrm{p}<0.05$ \\
Poses & $7.3 \pm 2.6$ & $10.1 \pm 2.6$ & $\mathrm{p}<0.05$ \\
Facial expressions & $18.3 \pm 2.7$ & $9.4 \pm 1.1$ & $\mathrm{p}<0.05$ \\
Tone of voice & $12.9 \pm 1.3$ & $7.2 \pm 1.2$ & $\mathrm{p}<0.05$ \\
\hline
\end{tabular}

riment of all measured biochemical parameters; decrease of SA level, instability and inadequacy of AL. They were characterized by outwardly more quiet behavior, less number of poses and gestures but more varied facial expressions and changes in voice tone.

- Patients, who differ from the above mentioned groups by moderate changes in physiological and psychological parameters under stress with optimal indices of emotion control, which brings them closer to the group of healthy individuals (9 patients, 5.3\% of participants with HTN).

Statistical data analysis showed that in the group of patients with HTN at work a phenomenon of excessive emotional repression was detected in 63\% of cases; openly anxious type of stress reaction-in 37\%. There were no patients with adaptive reaction to stress in this group. This is consistent with data obtained in other studies [10]-[13].

Most patients with essential HTN show the openly anxious type of reaction (69\% of cases). The repressive type of reaction is present in $20 \%$ of cases; and that of adaptive-in $10 \%$ of patients.

There is an assumption, prevailing in contemporary publications, that emotion repression comes as a leading psychological factor of psychosomatic syndrome genesis in patients with HTN [11] [15] [16]. The qualitative data analysis of our results brings us to conclude that this cannot be accounted for pathogenesis of all HTN forms. Emotion repression phenomenon, according to our data, is particularly specific for patients with HTN at work.

Vygotsky-Luria's syndrome analysis of this data as well as analysis and interpretation of the whole set of the results of the study lead to the conclusion that HTN at work possess a steady, meaningfully interpreted complex of clinical and psychological symptoms and syndromes that may be defined as a psychosomatic syndrome.

Results of the qualitative analysis of the data lead us to assert that the features of motivation sphere of patientsthe domination of achievement motivation-appear as the main factor generating the psychological syndrome. This conclusion was drawn on the basis of Luria's principles for psychological factors (causes) selection, which determine the logic and structure of a neuropsychological syndrome, and on the interpretation of the results of cluster analysis.

A persistent combination of the described features of the motivation sphere, with insufficient control over motivations and emotions and suboptimal ways of resolving emotiogenic situations, and certain peculiarities of the emotional experience of patients with HTN at work in stress situations suggest that the structure of this psychosomatic syndrome features one more psychological factor: dysfunction of emotion regulation. This psychological factor is bipolar. It is represented in two extremes: on the one hand, excessive emotional repression (this is more typical for HTN at work patients), and insufficient emotional control, on the other.

The factor of repression and denial of the significance of an alarming situation is the third syndrome-generating factor, according to the statistical and qualitative analysis. 
Thus, the results confirmed the hypothesis about the multifactorial structure of psychosomatic syndrome, which is typical for patients with HTN at work. These results also verified validity of the assumption that factors generating psychosomatic syndrome have a multilevel structure. In the structure of the described factors we can distinguish the morpho-functional, psychophysiological and psychological levels. And furthermore, in the structure of a psychological level there can be allocated levels of voluntary and involuntary regulation (e.g., voluntary and involuntary emotion regulation).

Reexamination of the patients after 5 years demonstrated that the psychosomatic syndrome has a stable structure, despite positive or negative dynamics in the patient's state. This feature sets prognosticating perspectives. The patients that had been assigned to the "risk group" for plausible symptomatology complications in accordance with clinical and psychological signs described above (as well as the whole complex of clinical and psychological features) confirmed our expectations of "hardening" of clinical HTN manifestations under conditions of emotional pressure, if medication and psychological aid had not been provided.

\section{Conclusions}

The psychosomatic syndrome in patients with HTN at work was described in accordance with the principles of the postnonclassical scientific paradigm, and the principles of psychological syndrome analysis (Vygotsky-Luria school). The obtained data suggest that the syndrome is system-defined and has a multifactorial and multi-level structure. That is, the structure of the psychosomatic syndrome in patients with HTN at work is determined by three factors, different from the neuropsychological syndrome, which is typically one-factorial [3] [4] [8].

These factors are as follows: the motivational factor (characterized by the domination of achievement motivation); the factor of emotion regulation disorder; and the factor of repression and denial of the significance of an alarming situation. We suggest that a psychosomatic syndrome analysis can be used for diagnostic and even prognostic tasks both in clinical psychology and medicine.

The results of our empirical study based on postnonclassical philosophy and methodology of psychological syndrome analysis obviously expand the scientific background of the nature of a particular disease- $-\mathrm{HTN}$ at work — and establish more fundamental issues in clinical psychology, neuroscience and medicine [17]-[22].

\section{References}

[1] Styopin, V.S. (2003) Samorazvivajuwiesja sistemy i postneklassicheskaja racional'nost' [Self-developing systems and postnonclassical rationality]. Voprosy Filosofii, 8, 5-17.

[2] Kornilova, T.V. and Smirnov, S.D. (2011) Metodologicheskie osnovy psihologii: Uchebnik [Methodological basics of psychology: Textbook]. 2nd Edition, Yurajt, Moscow.

[3] Zinchenko, Yu.P. and Pervichko, E.I. (2012) The Methodology of Syndrome Analysis within the Paradigm of "Qualitative Research” in Clinical Psychology. Psychology in Russia: State of the Art, 5, 157-184.

[4] Zinchenko, Yu.P., Pervichko, E.I. and Martynov, A.I. (2013) Psychological Underpinning of Personalized Approaches in Modern Medicine: Syndrome Analysis of Mitral Valve Prolapsed Patients. Psychology in Russia: State of the Art, 6, 89-102.

[5] Zinchenko, Y., Pervichko, E. and Martynov, A. (2013) Emotional Experiences and Coping Processes in the Context of Verification of Psychosomatic Hypotheses in MVP Patients. Procedia-Social and Behavioral Sciences, 86, 47-52.

[6] Zinchenko, Y.P. and Pervichko, E.I. (2013) Nonclassical and Postnonclassical Epistemology in Lev Vygotsky’s Cultural-Historical Approach to Clinical Psychology. Psychology in Russia: State of the Art, 6, 43-56.

[7] Vygotsky, L.S. (1993) The Diagnostics of Development and the Pedological Clinic for Difficult Children. In Rieber, R.W., \& Carton, A.S., Eds., The Collected Works of L. S. Vygotsky: The Fundamentals of Defectology (Abnormal Psychology and Learning Disabilities), Plenum Press, New York, 2, 241-291.

[8] Luria, A.R. (1973) The Working Brain. An Introduction to Neuropsychology. Penguin Books, London.

[9] Stork, J., Schrader, J., Mann, H. and Noring, R. (1992) Einflu BS der beruflichen Tatigkeit auf den Blutdruckverlaufuber 24 Stunden. Nieren und Hochdruckkrankheiten, 10, 466-468.

[10] Karasek, R. (1998) Demand/Control Model: A Social, Emotional, and Physiological Approach to Stress Risk and Active Behaviour Development. In: Stellman, J.M., Ed., Encyclopaedia of Occupational Health and Safety, International Labour Office, Geneva, 34.6-34.14.

[11] O’Donnell, K., Brydon, L., Wright, C. and Steptoe, A. (2008) Self-Esteem Levels and Cardiovascular and Inflammatory Responses to Acute Stress. Brain, Behavior, and Immunity, 22, 1241-1247. 
http://dx.doi.org/10.1016/j.bbi.2008.06.012

[12] Chandola, T., Britton, A., Brunner, E., Hemingway, H., Malik, M., Kumari, M., Badrick, E., Kivimaki, M. and Marmot, M.G. (2008) Work Stress and Coronary Heart Disease: What Are the Mechanisms? European Heart Journal, 29, 640648. http://dx.doi.org/10.1093/eurheartj/ehm584

[13] Pervichko, E., Zinchenko, Y. and Ostroumova, O. (2013) Personal Factors of Emotional Burnout in Patients with "Hypertension at Work". Procedia-Social and Behavioral Sciences, 86, 407-412.

[14] Pervichko, E., Zinchenko, Yu. and Ostroumova, O. (2013) Violations of Emotional Regulation in Patients with StressInduced Hypertension. Procedia-Social and Behavioral Sciences, 78, 295-299.

[15] Nicole, A., Roberts, N.A., Levenson, R.W. and Gross J.J. (2008) Cardiovascular Costs of Emotion Suppression cross Ethnic Lines. International Journal of Psychophysiology, 70, 82-87. http://dx.doi.org/10.1016/j.ijpsycho.2008.06.003

[16] Garnefski, N., Koopman, H., Kraaij, V. and ten Cate, R. (2009) Brief Report: Cognitive Emotion Regulation Strategies and Psychological Adjustment in Adolescents with a Chronic Disease. Journal of Adolescence, 32, 449-454. http://dx.doi.org/10.1016/j.adolescence.2008.01.003

[17] Han, S., Fan, Y., Xu, X., Qin, J., Wu, B., Wang, X., Aglioti, S.M. and Mao, L. (2009) Empathic Neural Responses to Others’ Pain Are Modulated by Emotional Contexts. Human Brain Mapping, 30, 3227-3237. http://dx.doi.org/10.1002/hbm.20742

[18] Mezzich, J.E., Salloum, I.M., Cloninger, C.R., Salvador-Carulla, L., Kirmayer, L., Banzato, C.E., Wallcraft, J. and Botbol, M. (2010) Person-Centered Integrative Diagnosis: Conceptual Bases and Structural Model. Canadian Journal of Psychiatry, 55, 701-708.

[19] Pöppel, E. and Wagner, B. (2012) Von Natur aus Kreativ. Hanser-Verlag, München. http://dx.doi.org/10.3139/9783446432864

[20] Pöppel, E., Avram, M., Bao, Y., Graupmann, V., Gutyrchik, E., Lutz, A., Park, M., Reiser, M., Russell, E., Silveira, S., Smigielski, L., Szymanski, C. and Zaytseva, Y. (2013) Sensory Processing of Art as a Unique Window into Cognitive Mechanisms: Evidence from Behavioral Experiments and fMRI Studies. Procedia—Social and Behavioral Sciences, 86, 10-17.

[21] Zinchenko, Y., Krasnov, V., Pervichko, E. and Kulygina, M. (2013) Russian Traditional and Postnonclassical Psychological Perspectives on Person-Centered Mental Health care. The International Journal of Person Centered Medicine, 3, 81-87.

[22] Mezzich, J.E., Zinchenko, Y.P., Krasnov, V.N., Pervichko, E.I. and Kulygina, M.A. (2013) Person-Centered Approaches in Medicine: Clinical Tasks, Psychological Paradigms, and Postnonclassic Perspective. Psychology in Russia: State of the Art, 6, 95-109. 